\title{
EDITORIAL
}

\section{Lifting the smokescreen}

\author{
J. Britton* and F. Godfrey ${ }^{\#}$
}

드 vidence on the health effects of exposure to secondhand tobacco smoke was first published in 1974 [1]. Since then, over 20 independent reports published by a range of organisations, ranging from the International Agency for Research on Cancer (IARC) [2], the Environmental Protection Agency (EPA) [3] and the German Maximale Arbeitsplatz Konzentration (MAK) Commission [4], have confirmed that exposure to second-hand smoke causes a range of chronic and fatal conditions, including ischaemic heart disease, stroke, lung cancer and chronic obstructive pulmonary disease. Whilst the magnitude of risk is small, the exposure of nonsmokers to second-hand smoke in Europe is widespread and, therefore, the potential harm is considerable.

In recent years, this growing level of irrefutable evidence has prompted health organisations to call for ever greater restrictions on smoking in work and public places. Legislation restricting smoking was introduced in several European countries in the early 1980s and 1990s, but European governments have been slow to recognise the full extent of the health problems caused by second-hand smoke. It was not until the state of California (USA), and then New York, moved towards the introduction of comprehensive legislation banning smoking in all workplaces, including bars and restaurants in 1998 and 2003, respectively, that Europe took real notice.

The first European country to do so was Ireland. The impetus for the law came from the committed political leadership shown by the then Health Minister, Micheal Martin, who commissioned a report into the health effects of passive smoking in Ireland. The Allwright report [5] once again highlighted the dangers to health from passive smoking, and found that workers in the Irish hospitality sector were most at risk from exposure to second-hand smoke. The authors of the report called upon Mr Martin to take steps to protect all workers from exposure by introducing a comprehensive ban on smoking in all enclosed workplaces, and he took immediate steps to implement the report's recommendations [6]. The law came into force on March 29, 2004.

Scientific research organisations working on tobacco-control policy at the European level recognised the need to identify the scale of the public health problem caused by passive smoking in the European Union (EU), and commissioned their own report in October 2004. On March 21, 2006, the European Respiratory Society (ERS), along with its partners in tobacco

${ }^{\star}$ Centre for Respiratory Research, University of Nottingham, Nottingham, UK. ${ }^{*}$ ERS Office, Brussels, Belgium.

CORRESPONDENCE: F. Godfrey, EU Policy Adviser, European Respiratory Society, 39-41 rue d'Arlon, Brussels, Belgium. Fax: 32 22385361. E-mail: fiona.godfrey@ersnet.org control at the European level (Cancer Research UK, the European Heart Network and the Institut National du Cancer), launched this report in the European Parliament, with the support of the Members of the European Parliament, Liz Lynne and Adamos Adamou. Lifting the smokescreen: 10 reasons for a smoke free Europe (available at www.ersnet.org) is the first attempt to provide an estimate of the number of deaths caused by exposure to second-hand smoke in the EU25 broken down by country, smoking status and type of exposure (workplace or domestic). It also includes chapters on the economic costs of passive smoking, an analysis of the economic benefits of smoke free workplace legislation and an assessment of the attitudes and opinions of Europeans in selected EU member states about such laws.

The report calculates the number of deaths from heart disease, stroke, lung cancer and non-neoplastic respiratory disease caused by passive smoking. Deaths in childhood caused by passive smoking, and cases of serious morbidity, both chronic and acute, caused by passive smoking were not calculated. The figure totalled 79,459 deaths per annum in the EU. Broken down, this resulted in 72,000 deaths from domestic exposure and $>7,000$ deaths from workplace exposure. Of these, $>19,000$ deaths were in nonsmokers. A total of 7,200 people were found to die each year from second-hand smoke exposure in the workplace, including 2,800 nonsmokers [7]. One employee in the EU hospitality industry dies every day from second-hand smoke exposure. Exposure to passive smoking in the home causes the deaths of 16,600 nonsmokers each year, or one death every 32 minutes [7].

The methodology used to calculate the number of deaths was the same as that used in the Royal College of Physicians report [8] on passive smoking and the published estimate of deaths from passive smoking in the UK [9]. Calculations of the figures for working age and elderly populations were derived from data in the World Health Organization (WHO) database [10]. For most countries, data were available for the proportion of the population aged $\geqslant 65$ and $\leqslant 15$ yrs. Data on smoking prevalence were also taken from the WHO database, along with data on the smoke free status of individual countries. Calculations of the employed population and hospitality industry workforce came from the Eurostat database of the EU Commission [11]. The UK figure of $27.8 \%$ of the hospitality workforce employed in pubs, bars and nightclubs was applied across the EU.

Given the lack of data entry points for some countries, the most conservative figure from what appeared to be the most similar country was taken. For this reason, the number of deaths calculated is likely to be an underestimate. 
The report also looked at the effects of smoking bans on quitting. A review of 26 studies in 2002 found that complete smoking bans in workplaces reduced smoking prevalence by $3.8 \%$ and smoking intensity by 3.1 cigarettes per day among continuing smokers [12]. Smoke free laws have also encouraged workers to make more quit attempts and these are likely to be more successful [13].

Lifting the smokescreen also analysed the economic effects of legislation banning smoking in the workplace [14]. A review of data collected in jurisdictions around the world found no reported negative economic effects arising from the introduction of smoke free laws in independent research studies. In New York, since the smoke free law came into force in March 2003, business tax receipts in restaurants and bars have increased by $8.7 \%$, employment in bars and restaurants has increased by 10,800 jobs and $97 \%$ of bars and restaurants are now smoke free [15].

Lifting the smokescreen reviewed poll data from 2002 to 2005 to assess support for smoke free legislation in several European countries [16]. International experience of successful smoke free policies suggests that there is a need for a reasonable level of public awareness of the dangers of passive smoking and a certain level of support. Recent polls across Europe have suggested that both are rapidly increasing. Based on levels of support for smoke free legislation in other jurisdictions, it is clear that support in several EU countries that have yet to go smoke free is several per cent higher than it was in other countries when they enacted laws [16]. Evaluation studies assessing the impact of smoke free laws pre- and post-entry into force have also found strong and increasing support from smokers once the laws have been successfully implemented. In Ireland, support for smoke free restaurants among smokers increased from $46 \%$ pre-enactment to $77 \%$ post-ban [17].

The importance of political leadership in building support for smoke free laws can be seen in a comparison of poll data from Scotland and England. One poll in Spring 2004 put support for smoke free pubs in Scotland at 39\% and 51\% in England. The Scottish First Minister subsequently announced his intention to introduce smoke free legislation, whereas the then England health minister opposed smoke free bars and restaurants. By December 2005, support for smoke free bars in Scotland had increased by $31 \%$. In England, it had increased but only by $11 \%$ [18].

Of course, the overriding rationale of campaigns for smoke free legislation has always been to protect workers. Research studies conducted before and after the Irish and Norwegian bans show that this has happened. A study of the air quality in Dublin pubs conducted before and after the smoking ban showed a $45 \%$ reduction in carbon monoxide levels in nonsmoking bar staff and a decrease of $36 \%$ in ex-smokers 1 year after the ban was implemented. Average particulate matter of $<2.5 \mu \mathrm{m}$ (PM2.5) levels decreased by $87.6 \%$ and PM10 levels fell by 53\% [19]. Similar results were published by the Norwegian Institute for Drug and Alcohol Research (SIRUS) [20].

The conclusions of Lifting the smokescreen are clear: passive smoking kills, and workers and members of the population must be protected from all exposure to second-hand tobacco smoke. Its recommendations are brief: the most effective way to protect workers and the public is to introduce a comprehensive smoking ban in all public and workplace enclosed spaces. If we take a baseline smoking prevalence rate of $30 \%$ across the EU and assume an average effect on smoking prevalence of only $1-2 \%$, this would translate into somewhere between 5 and 10 million EU smokers quitting as a result of such legislation.

With public health gains of this magnitude there for the taking, and science and public support on our side, respiratory physicians and medical societies must now call upon all Europe's governments to implement comprehensive smoke free laws as soon as possible.

\section{REFERENCES}

1 Harlap S, Davies AM. Infant admissions to hospital and maternal smoking. Lancet 1974; 1: 529-532.

2 WHO International Agency for Research on Cancer. IARC monographs on the evaluation of the carcinogenic risk of chemicals to humans: tobacco smoking. Vol. 38. Lyon, IARC Press, 1986.

3 US Environmental Protection Agency. Respiratory health effects of passive smoking: lung cancers and other disorders. Washington, US Environmental Protection Agency, 1992.

4 Passive smoking. In: Occupational toxicants. Vol. 13. Commission for the Investigation of Health Hazards of Chemical Compounds in the Work Area. Greim H, WileyVCH, eds. Weinheim, 1999; pp. 3-39.

5 Report on the health effects of environment tobacco smoke (ETS) in the workplace. Dublin, Office of Tobacco Control and Health and Safety Authority, 2002.

6 Public Health (Tobacco) Act 2002 (Section 47) Regulations 2003. www.irishstatutebook.ie/ZZSI481Y2003.html. Date last accessed: March 152006.

7 Jamrozik K. An estimate of deaths attributable to passive smoking in Europe. In: Smoke free Partnership. Lifting the smokescreen: 10 reasons for a smoke free Europe. Brussels, ERSJ Ltd, 2006; pp. 17-41.

8 Royal College of Physicians. Going smoke-free: the medical case for clean air in the home, at work and in public places. London, Royal College of Physicians, 2005.

9 Jamrozik K. Estimate of deaths among smokers in the United Kingdom attributable to passive smoking, database analysis. BMJ 2005; Epub ahead of print.

10 World Health Organization Regional Office for Europe. Data and publications. http://data.euro.who.int. Date last accessed: March 152006.

11 Eurostat European Commission. http://epp.eurostat.cec. eu.int. Date last accessed: March 152006.

12 Fichtenberg CM, Glantz SA. Effect of smoke-free workplaces on smoking behaviour: systematic review. BMJ 2002; 325: 188-191.

13 Farkas A, Gilpin E, Distefan J, Pierce JP. The effects of household and workplace smoking restrictions on quitting behaviours. Tob Control 1999; 8: 261-265.

14 Joossens L. Economic impact of a smoking ban in bars and restaurants. In: Smoke free Partnership. Lifting the 
smokescreen: 10 reasons for a smoke free Europe. Brussels, ERSJ Ltd, 2006; pp. 63-83.

15 New York City. The State of Smokefree New York City. A one year review. NYC, 2004.

16 Jones S, Muller T. Public attitudes to smoke free policies in Europe. In: Smoke free Partnership. Lifting the smokescreen: 10 reasons for a smoke free Europe. Brussels, ERSJ Ltd, 2006; pp. 85-103.

17 Office of Tobacco Control. Smokefree at work one year review. Ireland, Office of Tobacco Control, 2005. www. otc.ie/article.asp? article $=271$. Date last accessed: March 15 2006.
18 YouGov, ASH, Cancer Research UK, 2005. Major new poll shows public support across UK for comprehensive smokefree law. www.ash.org.uk/html/press/051230.html. Date last accessed: March 152006.

19 Macaffrey M, Goodman P, Clancy L. Particulate pollution and benzene levels in public houses in Dublin pre and post-ban. Research Institute for a Tobacco Free Society, 2005.

20 Lund M. Smokefree bars and restaurants in Norway. Oslo, SIRUS, 2005. www.sirus.no/cwobjekter/ smokefreebarsandrestaurantsinNorway.pdf. Date last accessed: March 152006. 